University of South Carolina

Scholar Commons

1990

\title{
Electrochemical Production of Hydrogen and Sulfur by Low- Temperature Decomposition of Hydrogen Sulfide in an Aqueous Alkaline Solution
}

\author{
A. A. Anani \\ Texas A \& M University - College Station \\ Z. Mao \\ Texas A \& M University - College Station \\ Ralph E. White \\ University of South Carolina - Columbia, white@cec.sc.edu \\ S. Srinivasan \\ Texas A \& M University - College Station \\ A. J. Appleby

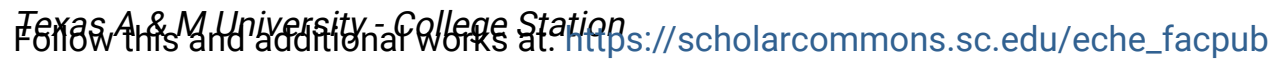 \\ Part of the Chemical Engineering Commons
}

\author{
Publication Info \\ Journal of the Electrochemical Society, 1990, pages 2703-2709. \\ (c) The Electrochemical Society, Inc. 1990. All rights reserved. Except as provided under U.S. copyright law, \\ this work may not be reproduced, resold, distributed, or modified without the express permission of The \\ Electrochemical Society (ECS). The archival version of this work was published in the Journal of the \\ Electrochemical Society. \\ http://www.electrochem.org/ \\ DOI: $10.1149 / 1.2087021$ \\ http://dx.doi.org/10.1149/1.2087021
}

This Article is brought to you by the Chemical Engineering, Department of at Scholar Commons. It has been accepted for inclusion in Faculty Publications by an authorized administrator of Scholar Commons. For more information, please contact digres@mailbox.sc.edu. 


\title{
Electrochemical Production of Hydrogen and Sulfur by Low- Temperature Decomposition of Hydrogen Sulfide in an Aqueous Alkaline Solution
}

\author{
A. A. Anani, ${ }^{*}$ Z. Mao, ${ }^{* *}$ R. E. White, ${ }^{*}$ S. Srinivasan, ${ }^{*}$ and A. J. Appleby \\ Center for Electrochemical Systems and Hydrogen Research, Texas A\&M University, College Station, Texas 77843
}

\section{ABSTRACT}

Electrolysis of hydrogen sulfide to its constituents in a solution containing equimolar concentrations of $\mathrm{NaOH}$ and NaHS has been carried out at $80^{\circ} \mathrm{C}$. In a double-compartment cell employing Nafion membrane as a separator, both crystalline elemental sulfur and high-purity hydrogen have been produced at high current efficiencies. Only minimal, if any, passivation of the anode by sulfur product was observed. According to solution composition, electrolysis could result in gas evolution at the anode, passivation of the anode by sulfur deposition, or oxidation of sulfide $\left(S^{2-}\right)$ or polysulfide $\left(S_{x}^{2-}\right)$ to sulfur oxyanions. However, in an optimized solution, electrolysis gave only anodic sulfur via bisulfide (HS ${ }^{-}$) and sulfide oxidation. Voltammetric and chronopotentiometric studies showed that sulfide, bisulfide, and polysulfide oxidation occurred at about the same potential.

Noring and Fletcher (1) pointed out some economic benefits that could arise from the production of elemental sulfur and hydrogen by electrolytic decomposition of hydrogen sulfide. To realize this goal, the problem of anode passivation by the sulfur produced must be solved. In direct electrolysis, the use of either hot organic vapor to remove the sulfur from the electrode surface (2) or organic solvents to extract sulfur from the solution (3) have been suggested. In indirect electrolysis, hydrogen sulfide is first oxidized to sulfur by a chemical reaction and the reduced oxidant is regenerated at the anode with simultaneous evolution of hydrogen at the cathode (4-7). Advantages of the direct process include a lower power input than that required to regenerate the reduced oxidant and that it will produce crystalline rather than colloidal sulfur, which is the normal product of indirect electrolysis.

Recently, direct electrolysis schemes without the use of solvents for sulfur have been proposed (8) or investigated $(9,10)$. In one of these $(9)$, it was reported that raising the temperature of electrolysis to $60^{\circ} \mathrm{C}$ can .eliminate the blocking effect. This approach required a continuous flow of hydrogen sulfide through the electrolytic cell, thereby shifting the $p H$ of the solution close to neutral values. In a separate publication (11), we have shown that these approaches involve problems such as low current efficiency, poor purity of the sulfur product and the formation of sulfur oxyanions. These will have to be overcome for the process to be commercially attractive. Further, analysis showed that the chemical, electrochemical, and mass transport processes involved in $\mathrm{H}_{2} \mathrm{~S}$ electrolysis under the conditions reported by Dandapani et al. (9) would be unlikely to result in sulfur precipitation from the anolyte, but would rather lead to anode passivation.

Our previous work (11) outlined the sequential steps (Fig. 1) which lead to complete electrolysis of hydrogen sulfide. Further, experimental results obtained from the electrolysis of hydrogen sulfide in alkaline solution are presented here. The conditions for efficient electrolysis are that the $\mathrm{pH}$ of the solution, thus the relative concentration of $\mathrm{NaOH}$ and $\mathrm{NaHS},{ }^{1}$ and the temperature are adequately controlled.

\section{Experimental}

Materials and materials preparation.-The solutions used in these experiments were prepared from deionized water and reagent-grade materials. High-purity hydrogen sulfide was obtained from Matheson Gas Company. The glass electrolytic cell, schematically shown in Fig. 2, con-

\footnotetext{
* Electrochemical Society Active Member.

${ }^{1}$ On saturation of a $\mathrm{NaOH}$ solution with hydrogen sulfide, $\mathrm{NaHS}$ is formed as a product via the reaction: $\mathrm{NaOH}+$ $\mathrm{H}_{2} \mathrm{~S} \rightarrow \mathrm{NaHS}+\mathrm{H}_{2} \mathrm{O}$. Results obtained from solutions of reagentgrade $\mathrm{NaHS}$ in this work were identical to those from solutions of $\mathrm{NaHS}$ produced by the reaction of $\mathrm{H}_{2} \mathrm{~S}$ and $\mathrm{NaOH}$.
}

sisted of two compartments separated by an ion-selective Nafion ${ }^{\circledR}$ membrane. Anode materials employed included graphite, nickel, porous nickel-chromium alloy, as well as titanium. Cathode materials were either nickel or graphite. Two $\mathrm{Hg} / \mathrm{HgO}(1 M \mathrm{NaOH})$ reference electrodes were separately connected to the anode and cathode compartments via Luggin capillaries and were utilized for monitoring half-cell potentials.

Experimental procedures.-Two groups of experiments are discussed in this work. In the first, hydrogen sulfide was bubbled continuously through the electrolytic cell before and during electrolysis. In the second, $\mathrm{H}_{2} \mathrm{~S}$ was $\mathrm{ab}$ sorbed in the $\mathrm{NaOH}$ scrubber, then introduced into a further compartment to adjust solution $\mathrm{pH}$ in the alkaline range. This solution was then introduced into the electrolytic cell. Conditions in the first group of experiments are the same as those reported by Dandapani et al. (9) where the electrolyte in the cell was essentially pure NaHS. In the second group of experiments, the electrolyte was NaHS plus $\mathrm{NaOH}$, in different ratios. In addition to these solutions, $\mathrm{Na}_{2} \mathrm{~S}_{4}$ was also examined as an electrolyte.

A Solartron Programmable Electrochemical Interface, Model 1286, was used as the power source for the cyclic

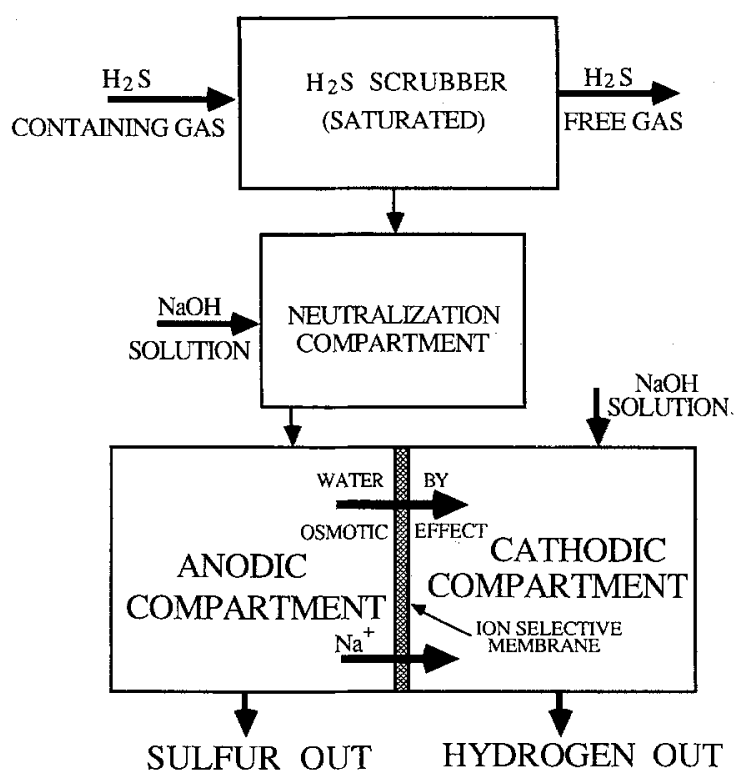

Fig. 1. Stepwise flow diagram for batch production of hydrogen and sulfur from hydrogen sulfide. The scrubber is an optimized concentrotion of sodium hydroxide solution for use in a cell to be operated at a temperature of about $80^{\circ} \mathrm{C}$. 


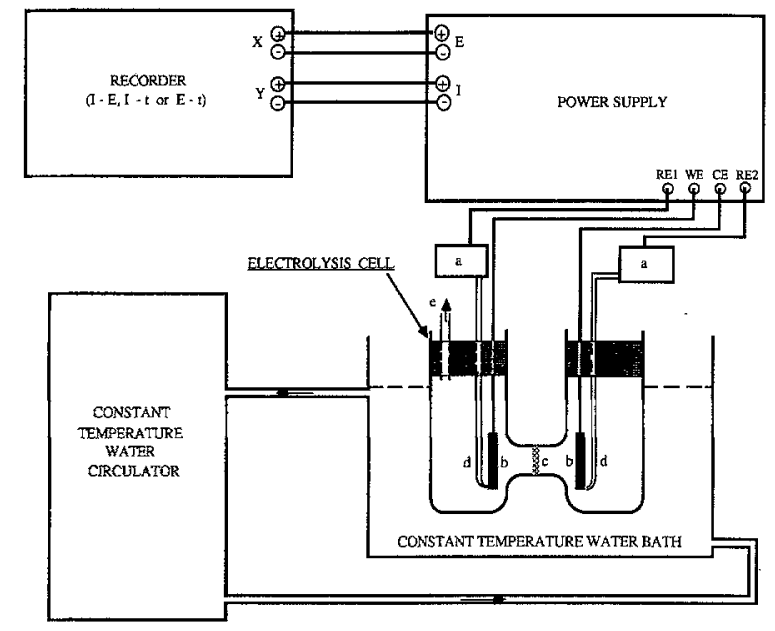

Fig. 2. Schematic laboratory experimental cell for $\mathrm{H}_{2} \mathrm{~S}$ electrolysis: (a) $\mathrm{Hg} / \mathrm{HgO}$ ( $1 \mathrm{M} \mathrm{NaOH}$ ) reference electrode; (b) active electrode area; (c) ion-selective membrane; (d) Luggin capillary; (e) hydrogen gas outlet; and $(f)$ lead-through seals.

voltammetric, chronopotentiometric, and galvanostatic studies. The results were monitored and recorded by Yokohawa X-Y and chart recorders Model 3025 and 3021, respectively, and an HP multimeter Model 3468A. All experiments were carried out at $80^{\circ} \mathrm{C}$. A constant temperature water circulator Model RMS Brimhan Instrument, Incorporated, was used to monitor and maintain the temperature.

Product analysis.-Current efficiency for hydrogen production was determined from the volume of gas produced at the cathode. Gas samples were analyzed using a gas chromatograph. Current efficiency for sulfur production was estimated by comparing the amount of coulombs passed during electrolysis with the difference between $\mathrm{HS}^{-}$concentrations before and after electrolysis. In addition, efficiencies were estimated from the amount of solid product collected which resulted in lower yields due to product losses during washing and filtering. The solid products were analyzed with a Tracor Northern 2000 EDS on a JEOL JSM-35CF scanning electron microscope. Sample materials were mounted on conductive carbonpainted aluminum stubs, which were then evaporatively coated with about $100 \AA$ of carbon for conduction. Analysis was carried out at $15 \mathrm{keV}$, with a beam current of $100 \mathrm{pA}$ for times ranging from 40 to $100 \mathrm{~s}$. The identity and phase purity of the product was confirmed using powder x-ray diffraction. A Picker $638 \mathrm{XRD}$ generating $\mathrm{Cu}_{\mathrm{K} \alpha}$ radiation interfaced with a PDP 11/23 computer under an RSX 11M operating system with in-house control and data gathering software was used for the analysis.

Since previous analysis (11) showed that sulfur can be precipitated near the anode from an equimolar $\mathrm{NaOH}: \mathrm{NaHS}$ solution by continued electrolysis, different ratios of $\mathrm{NaOH}$ to $\mathrm{NaHS}$ were used as anolytes with $1 M$ $\mathrm{NaOH}$ catholyte. The initial volumes of both before electrolysis was $25 \mathrm{ml}$. Electrolysis was carried out galvanostatically.

\section{Results and Discussion}

Galvanostatic studies.-Electrolyte concentration ratio $(\mathrm{NaOH}: \mathrm{NaHS})=0: 1$. - The as-prepared $1 \mathrm{M}$ NaHS solution was slightly yellow. The steady-state open-circuit potential of the anode was $-0.57 \mathrm{~V}$ vs. $\mathrm{Hg} / \mathrm{HgO}$ ( $1 M \mathrm{NaOH})$. Upon electrolysis at $20 \mathrm{~mA} / \mathrm{cm}^{2}$, the overpotential gradually increased from an initial value of $-0.4 \mathrm{~V}$ and the solution became deeper yellow. With continued electrolysis, the potential rose sharply to $1.8 \mathrm{~V}$ with accompanying gas evolution. The sharp rise in overpotential may result from precipitation of an insulating sulfur layer on the electrode surface. At this point only a very low current density $\left(5 \mathrm{~mA} / \mathrm{cm}^{2}\right)$ could be applied at a low overpotential. Electrolysis was terminated when a black coating formed on the anode and the overpotential rose to a value where gas evolution again occurred. The total amount of charge passed during this time was equivalent to only about $50 \%$ of the total sulfur content in the anolyte solution.

The black coating from the electrode surface was heated in a glass ampul. Yellow vapor was observed to condense on its walls when the temperature was slightly above the melting point of sulfur.

The $\mathrm{pH}$ of the bulk anolyte decreased from an initial value of 12.6 to 9.4 when electrolysis was terminated, suggesting that the $\mathrm{pH}$ at the electrode/electrolyte interface was even lower during electrolysis. As a result, any sulfurformed deposits on the electrode surface without further chemical reaction to give polysulfide species, as is the case at higher $\mathrm{pH}$ values, i.e., higher $\mathrm{NaOH}: \mathrm{NaHS}$ ratios.

Electrolyte concentration ratio ( $\mathrm{NaOH}: \mathrm{NaHS})=$ 1:1.-The color of this solution was yellow, turning to light orange upon continued electrolysis at $20 \mathrm{~mA} / \mathrm{cm}^{2}$. The electrode potential at this current density was more positive than $-0.4 \mathrm{~V} v s . \mathrm{Hg} / \mathrm{HgO}$ and was constant until $\mathrm{ca} .60 \%$ of the total sulfide content of the solution was oxidized, when it increased sharply to $+0.5 \mathrm{~V} v s$. $\mathrm{Hg} / \mathrm{HgO}$. Stirring restored the potential to the previous value, suggesting that the electrolyte at the interface was depleted of the electroactive species. On continued electrolysis, no further rise in potential was observed, so long as the solution was continuously agitated, so no surface blocking or coating by sulfur occurred. When the solution was not stirred, electrolysis was carried out at $5 \mathrm{~mA} / \mathrm{cm}^{2}$ to prevent the anode potential from reaching values where sulfur oxyanions might form. After ca. $\mathbf{8 5 \%}$ of the total sulfur content was oxidized, the current was again increased to $20 \mathrm{~mA} / \mathrm{cm}^{2}$, when yellow precipitates formed on the electrode surface and continuously fell from the electrode. This process was accompanied by a slight increase in the electrode potential. Continuous application of current resulted in a sharp rise of the potential to about $+1.4 \mathrm{~V} v \mathrm{~s}$. $\mathrm{Hg} / \mathrm{HgO}$, giving a colorless solution and gas evolution. Electrolysis was then terminated. Very little increase in potential occurred during electrolysis, therefore blocking effects were eliminated. The $\mathrm{pH}$ of the anolyte changed from 13.4 to $9.6 \mathrm{dur}-$ ing electrolysis.

Figure 3 shows polarization curves for the anode at different stages of electrolysis, corresponding to the oxidation of sulfide species to sulfur. The lowest potential for this conversion corresponded to ca. $25 \%$ conversion of the initial sulfur present. Further electrolysis resulted in an increase in anode potential, possibly attributable to concentration polarization and $p \mathrm{H}$ changes.

The anolyte was filtered, and the yellow precipitate was characterized using XRD and EDS techniques. The $\mathrm{x}$-ray diffraction pattern is shown in Fig. 4, and indicates a crystalline orthorhombic structure, i.e., $\alpha$-sulfur. Figure 5 is a representative EDS spectrum at $15 \mathrm{kV}$ illumination, showing a strong sulfur peak with a trace amount of silicon. The

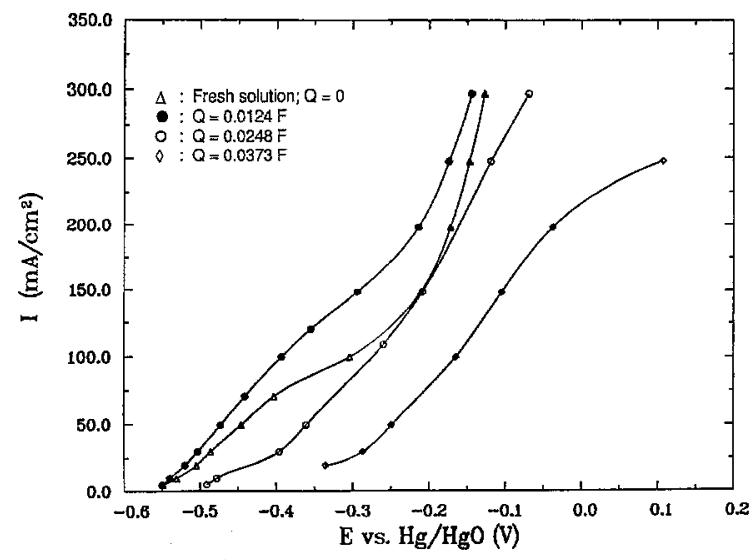

Fig. 3. Polarization curves at different stages of electrolysis in a $1: 1$ NaHS: $\mathrm{NaOH}$ solution. $Q$ is the total amount of charge passed in unit of faraday, (F). A Q-value of $5 \times 10^{-2} \mathrm{~F}$ is equivalent to $100 \%$ sulfur consumption in the initial anolyte solution. 


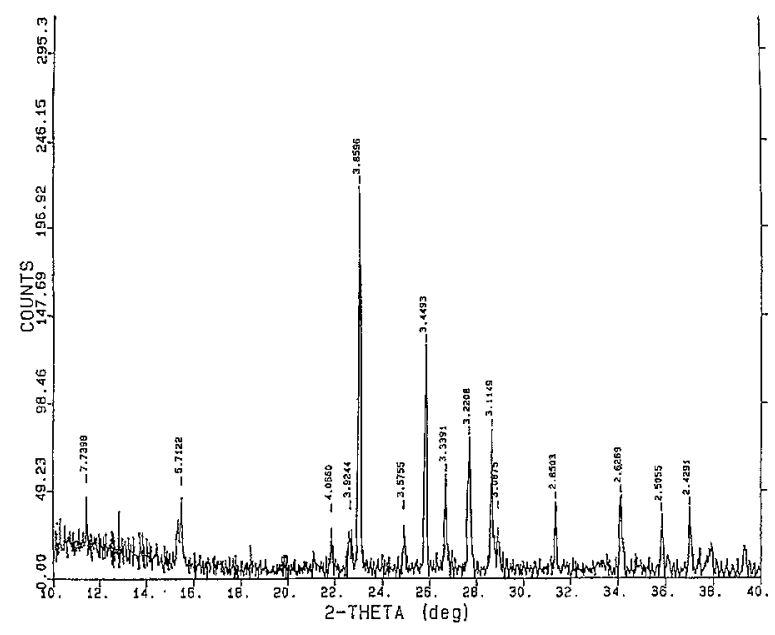

Fig. 4. X-ray diffraction pattern of electrolysis product. Numbers above peaks indicate corresponding $\mathrm{d}$-spacing for $\mathrm{Cu}-\mathrm{K} \alpha$ radiation.

relative intensities of the $\mathrm{S}: \mathrm{Si}$ peaks should not be used as a measure of sample composition since sulfur deteriorates rapidly under the beam compared with Si. However, after $43 \mathrm{~s}$ of beam exposure time, the nominal composition was 98.63:1.32:0.05 atom percent (a/o) (S:Si:Na). Silicon in the product may result from slight dissolution of the glass cell.

As expected, the conversion efficiency for sulfur production estimated gravimetrically is less than that estimated coulometrically. Table I lists the weights of the solid product and the estimated efficiencies for three different electrolysis runs from solutions of $1: 1 \mathrm{NaOH}$ : NaHS molar ratios. Estimated efficiency values are between 60 and $70 \%$ of the zero valence sulfur content of the initial anolyte solution. In comparison, however, the current efficiency estimated from the total coulombs passed during electrolysis was about $100 \%$.

Electrolyte concentration ratio $(\mathrm{NaOH}: \mathrm{NaHS})=1.5: 1$ Unlike the previous experiment, neither sulfur deposition nor gas evolution was observed at the anode on electrol. ysis, even when the amount of charge passed exceeded $150 \%$ of the total sulfur species in solution. A possible explanation is that further oxidation of polysulfide species to sulfur oxyanions had taken place. This is possible because of the high $\mathrm{pH}$ of the solution, which only changed from an as-prepared value of 13.7 to 13.3 , when electrolysis was terminated.

In all of the above three anolyte solutions, the catholyte remained colorless during electrolysis, showing that transfer of sulfide species to the cathode compartment was small. Thus, the cathode process was reduction of water to hydrogen close to $100 \%$ efficiency. The cathode gas product was collected over water and analyzed using a gas chromatograph. Its normalized composition was $99.97 \%$ hydrogen.

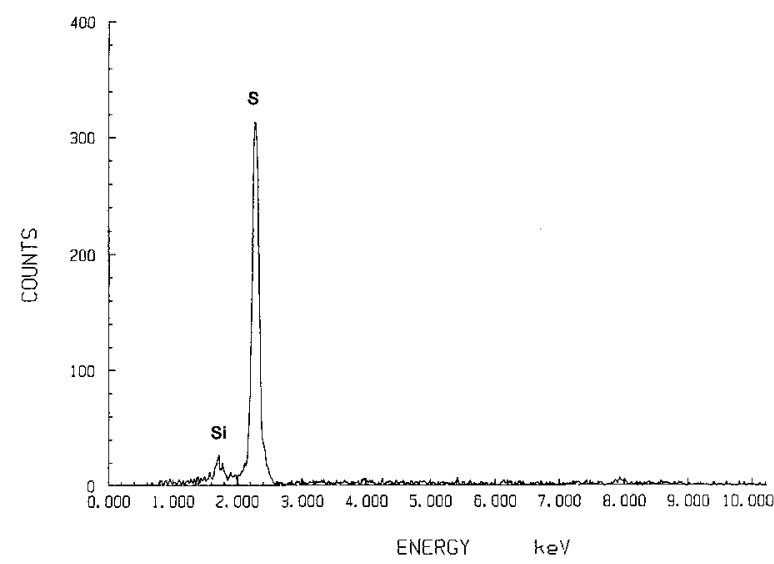

Fig. 5. EDS spectrum of product sample
Table I. Measured weight of product sulfur and corresponding current efficiency for sulfur production during $\mathrm{H}_{2} \mathrm{~S}$ electrolysis in an aqueous alkaline solution.

\begin{tabular}{ccc}
\hline Run number & $\begin{array}{c}\text { Weight of sulfur collected } \\
(\mathrm{g})\end{array}$ & $\begin{array}{c}\text { a Percent of initial } \\
\text { anolyte content }\end{array}$ \\
\hline Run 1 & 0.529 & 66 \\
Run 2 & 0.481 & 60 \\
Run 3 & 0.497 & 62 \\
\hline
\end{tabular}

a This percentage is based on $25 \mathrm{ml}$ of the anolyte used in the experiment, and translates for a $1: 1(\mathrm{NaHS}: \mathrm{NaOH})$ molar solution to $0.8015 \mathrm{~g}$ of sulfur.

Optimal electrolyte concentration.-The results have demonstrated the feasibility of hydrogen sulfide electrolysis at high conversion efficiencies in an equimolar $\mathrm{NaOH}: \mathrm{NaHS}$ solution to produce hydrogen and crystalline sulfur, the latter with minimal passivation. During electrolysis, water was transported across the membrane from the anodic to the cathodic compartment, as noted by a change in level. The formation of sulfur results in the migration of cation $\left(\mathrm{Na}^{+}\right)$from the anodic compartment, through the membrane, to the cathodic compartment to preserve charge neutrality. At the anode, $\mathrm{OH}^{-}$species are consumed in the typical process

$$
\mathrm{NaHS}+\mathrm{OH}^{-} \rightarrow \mathrm{S}+\mathrm{H}_{2} \mathrm{O}+\left(\mathrm{Na}^{+}\right)+2 e^{-}
$$

The $p \mathrm{H}$ is therefore reduced at the anode, with production of water in the electrolyte. $\mathrm{Na}^{+}$and $\mathrm{H}_{2} \mathrm{O}$ migrate through the membrane to the cathode, where $\mathrm{H}_{2} \mathrm{O}$ is consumed

$$
\left(\mathrm{Na}^{+}\right)+\mathrm{H}_{2} \mathrm{O}+e^{-} \rightarrow \frac{1}{2} \mathrm{H}_{2}+\mathrm{NaOH}
$$

Thus, the catholyte volume increases. Figure 6 shows the catholyte volume increase as a function of charge passed in electrolysis for initial catholyte and anolyte volumes of $25 \mathrm{ml}$. The potential difference across the membrane, measured by two reference electrodes on either side on current interruption, shows the same trend. This is shown in Fig. 7 and is due to the concentration difference across the anode-cathode compartments.

Cyclic voltammetric studies.-In this study, cyclic voltammetry on graphite electrodes was carried out after different elapsed electrolysis times. The electrodes were small enough to prevent changes in overall composition. The anolyte solutions used were $1 M \mathrm{NaHS}, 1 M \mathrm{NaHS}+1 M$ $\mathrm{NaOH}, 0.34 \mathrm{M} \mathrm{Na}_{2} \mathrm{~S}_{4}$, and $0.25 \mathrm{M} \mathrm{Na}_{2} \mathrm{~S}_{4}+0.25 \mathrm{M} \mathrm{NaOH}$. Expressed in terms of $\mathrm{NaOH}$ molar ratio, these are $0: 1(\mathrm{NaHS})$, 1:1(NaHS), $0: 1\left(\mathrm{Na}_{2} \mathrm{~S}_{4}\right)$, and $1: 1\left(\mathrm{Na}_{2} \mathrm{~S}_{4}\right)$, respectively. The catholyte was always $1 M \mathrm{NaOH}$ initially.

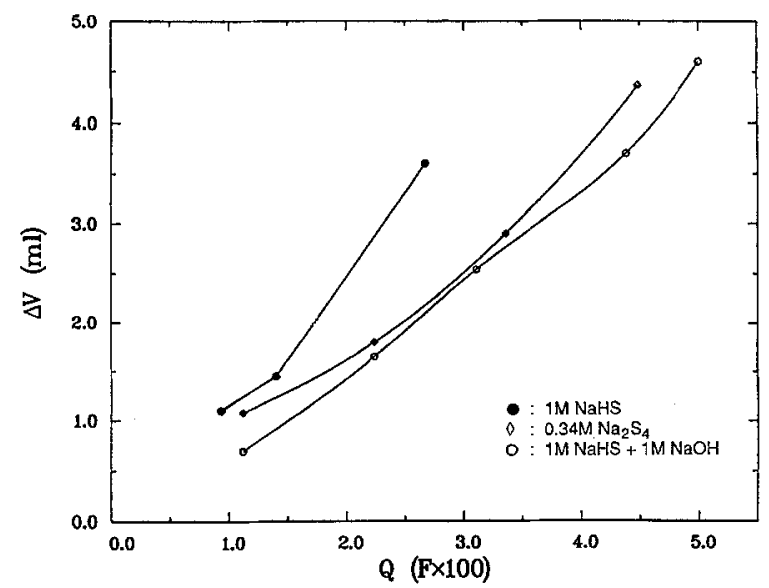

Fig. 6. Volume increase of catholyte solution as a function of extent of electrolysis. Initial anolyte and catholyte volume was each $25 \mathrm{ml}$. The catholyte was a $1 \mathrm{M} \mathrm{NaOH}$ solution while the different anolyte solutions are shown in the figure legend. 


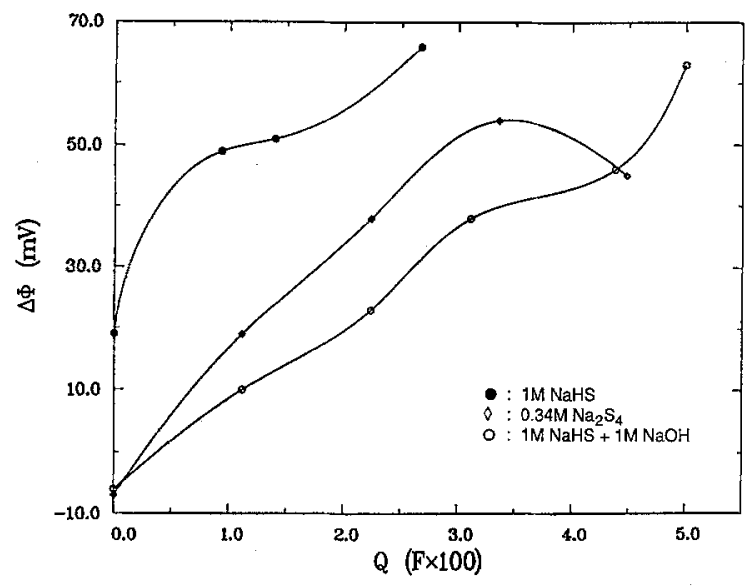

Fig. 7. Inter-relationship between the steady-state potential difference across the membrane and the extent of electrolysis expressed in terms of the total amount of charge $(Q)$ passed, in units of faraday. Initial catholyte and anolyte volume was $25 \mathrm{ml}$. Concentrations in legend represent different anolyte solutions for a $1 \mathrm{M} \mathrm{NaOH}$ catholyte solution.

Cyclic voltammograms prior to electrolysis are shown in Fig. 8. They all exhibit one broad anodic peak and a narrow cathodic peak near their open-circuit potentials, with an indication of a current increase at more positive potentials. However, two major characteristics may be noted: $(i)$ the cathodic peak for polysulfide reduction is smaller in $\mathrm{NaHS}$-containing solutions than in $\mathrm{Na}_{2} \mathrm{~S}_{4}$-containing solu-
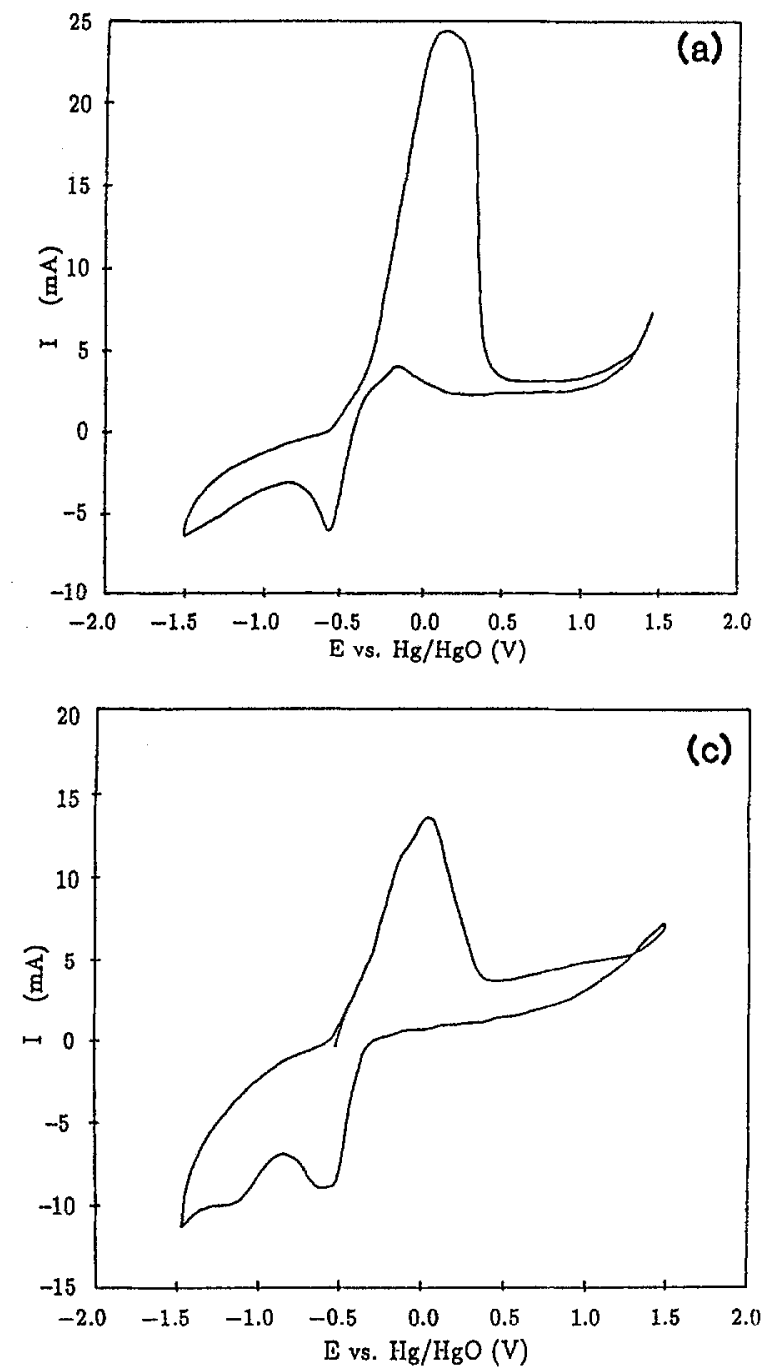

tions, which may be attributed to the known absence of polysulfide species in the fresh NaHS solutions; (ii) there is a sharp reduction in current after the anodic peak in solutions without $\mathrm{NaOH}$ due to the formation of a passivating layer, whereas in equimolar $\mathrm{NaOH}$ solutions, the decrease occurs over a wider potential range. No evidence of bubble formation was observed during the second anodic current rise, implying that this may be due to further oxidation of polysulfide species. From the peak width, the anodic process may result from at least two successive electrode reactions, as is shown by the two peaks resolved at low scan rates (Fig. 9). The cathodic process is due to a simple reduction of polysulfide species or absorbed sulfur to sulfide ions.

If the reactions occurring near the anodic peak convert sulfide or low polysulfide to higher polysulfides, then electrolysis at a low overpotential should consume only these reactant species. Thus, the height of the anodic peak should decrease with electrolysis time. This is shown in voltammograms obtained after a fraction of the total sulfur has been oxidized (Fig. 10). The cathodic peak, however, becomes larger, and Fig. 11 shows the anodic peak heightsquare root of sweep rate relationship, which is linear, showing that reaction is under diffusion control. To confirm whether the first peak height corresponds only to the concentration of sulfide species, the voltammograms were obtained after bubbling $\mathrm{H}_{2} \mathrm{~S}$ through the solution, which produced a higher first anodic peak (Fig. 11).

Voltammograms in the cathodic compartment were identical at different stages of electrolysis in all cases. These results suggest that diffusion of polysulfide species from the anode to the cathode compartments through the membrane is negligible.
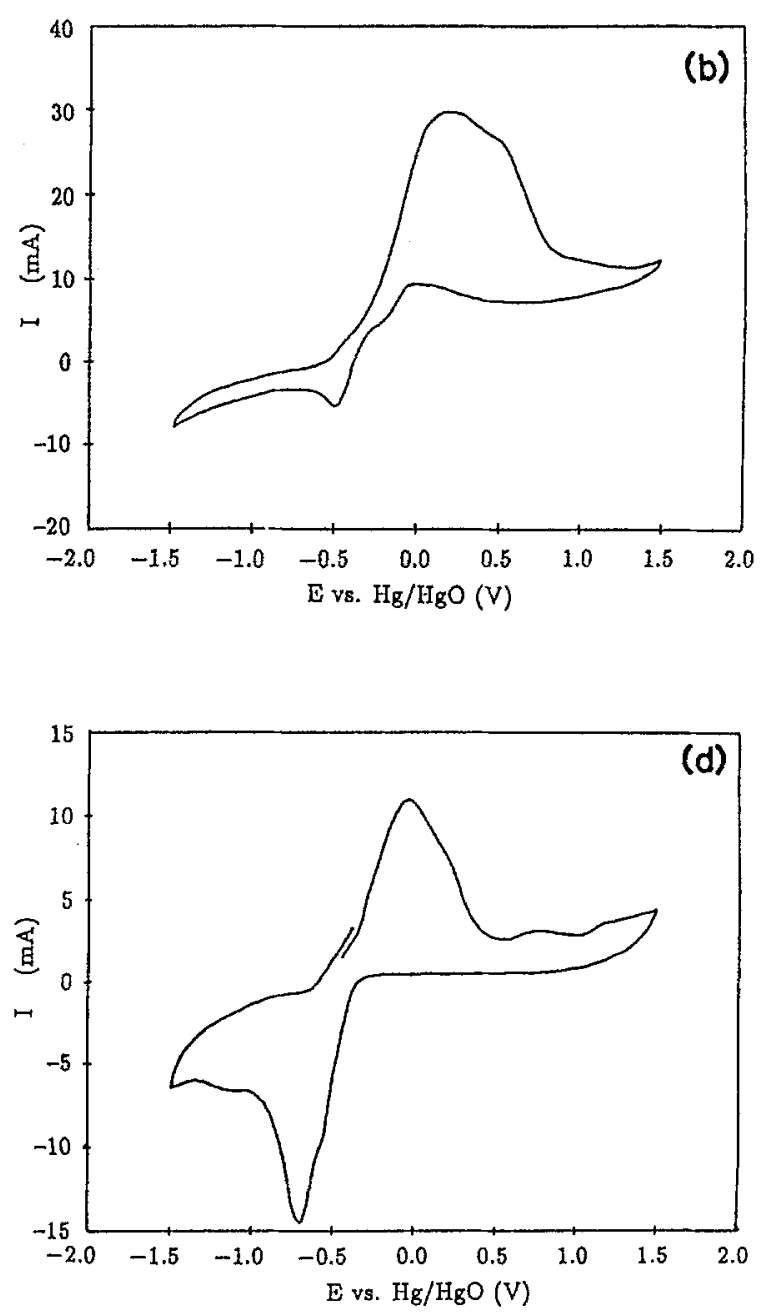

Fig. 8. Cyclic voltammograms for a graphite electrode from "as-prepared" solutions of different $\mathrm{NaHS:NoOH}$ ratios. Electrode area: $0.0707 \mathrm{~cm}^{-2}$; potential sweep rate: $100 \mathrm{mV} / \mathrm{s}$. (o) $1 \mathrm{M} \mathrm{NaHS}$; (b) $1 \mathrm{M} \mathrm{NaHS}+1 \mathrm{M} \mathrm{NaOH}$; (c) $0.34 \mathrm{M} \mathrm{Na} \mathrm{S}_{4}$; and (d) $0.25 \mathrm{M} \mathrm{Na}_{2} \mathrm{~S}_{4}+0.25 \mathrm{M} \mathrm{NaOH}$. 


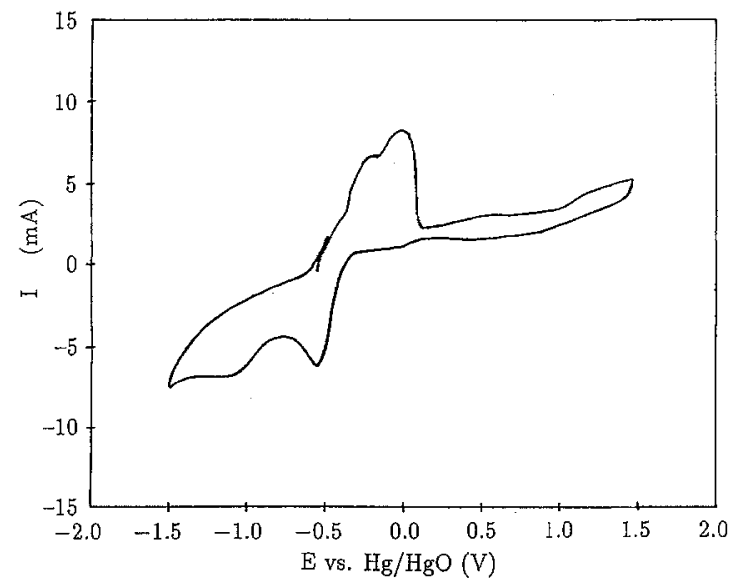

Fig. 9. Cyclic voltammogram for a graphite electrode in a freshly prepared $0.34 \mathrm{M} \mathrm{Na} \mathrm{S}_{4}$ solution showing split of anodic peak near the open-circuit potential. Scan rate was $25 \mathrm{mV} / \mathrm{s}$ on a $0.0707 \mathrm{~cm}^{2}$ surface area electrode.

Chronopotentiometric studies.-Under constant current electrolysis conditions over an extended period of time, it was observed that the anode potential first decreases and then gradually increases (see for example, Fig. 3). This result is consistent with galvanostatic polarization measurements and may be attributed to a self-catalytic reaction Short-term chronopotentiometric behavior of a graphite electrode, first in a freshly prepared 1:1 (NaOH:NaHS) solution (Fig. 12), and second, after several coulombs have been passed (Fig. 13), reveal characteristic features which indicate that the reaction involves parallel oxidation of two or more electroactive species. This indication is supported by the broadening of the anodic peaks in the vol-
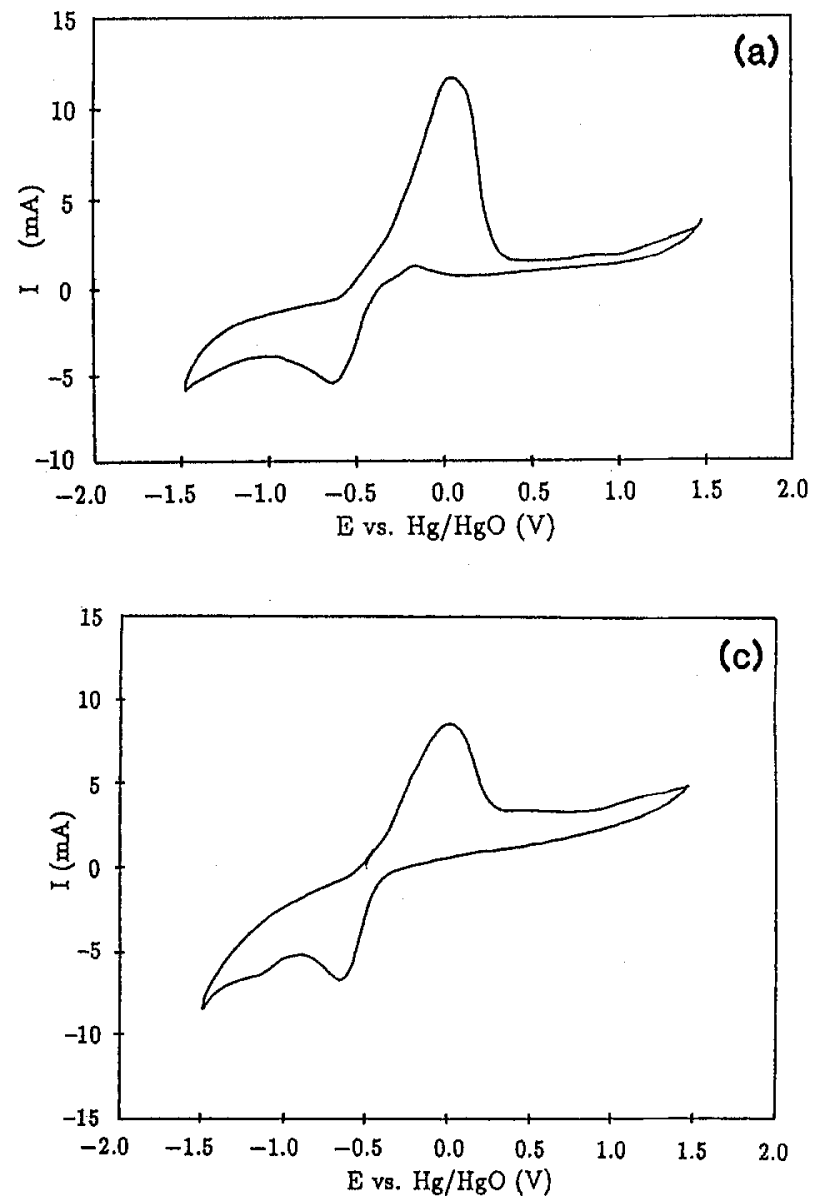

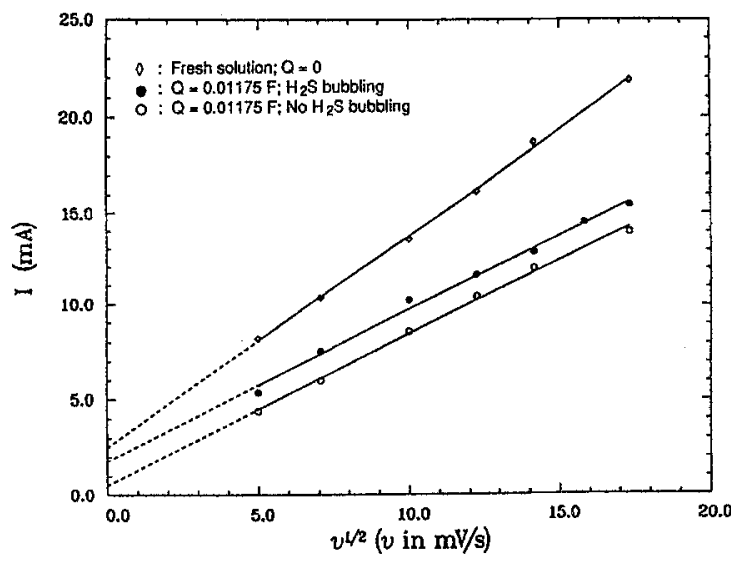

Fig. 11. A representative plot of the peak current vs. the square root of the scan rate before and during electrolysis. Plot is shown for a $0.34 \mathrm{M} \mathrm{Na}_{2} \mathrm{~S}_{4}$ solution with the effect of $\mathrm{H}_{2} \mathrm{~S}$ bubbling. Sweep conditions are the same as in Fig. 10.

tammograms (Fig. 8) and also by the $p \mathrm{H}$ of the initial solution which suggests equilibrium concentrations of both $\mathrm{HS}^{-}$and $\mathrm{S}^{2-}$.

Table II shows a generalized list of possible chemical and electrochemical reactions that might occur involving species that are $p \mathrm{H}$ and/or temperature dependent. A1though formation of higher polysulfides is possible, currents at the initial stages of electrolysis are predominantly controlled by the oxidation of $\mathrm{HS}^{-}, \mathrm{S}^{2-}$, and $\mathrm{S}_{2}^{2-}$. At the onset of electrolysis, $S_{2}^{2-}$ is absent and current results mainly from the oxidation of $\mathrm{HS}^{-}$and/or $\mathrm{S}^{2-}$. A corresponding initial increase in anode potential results, which may be due to depletion of reactant species at the anode/
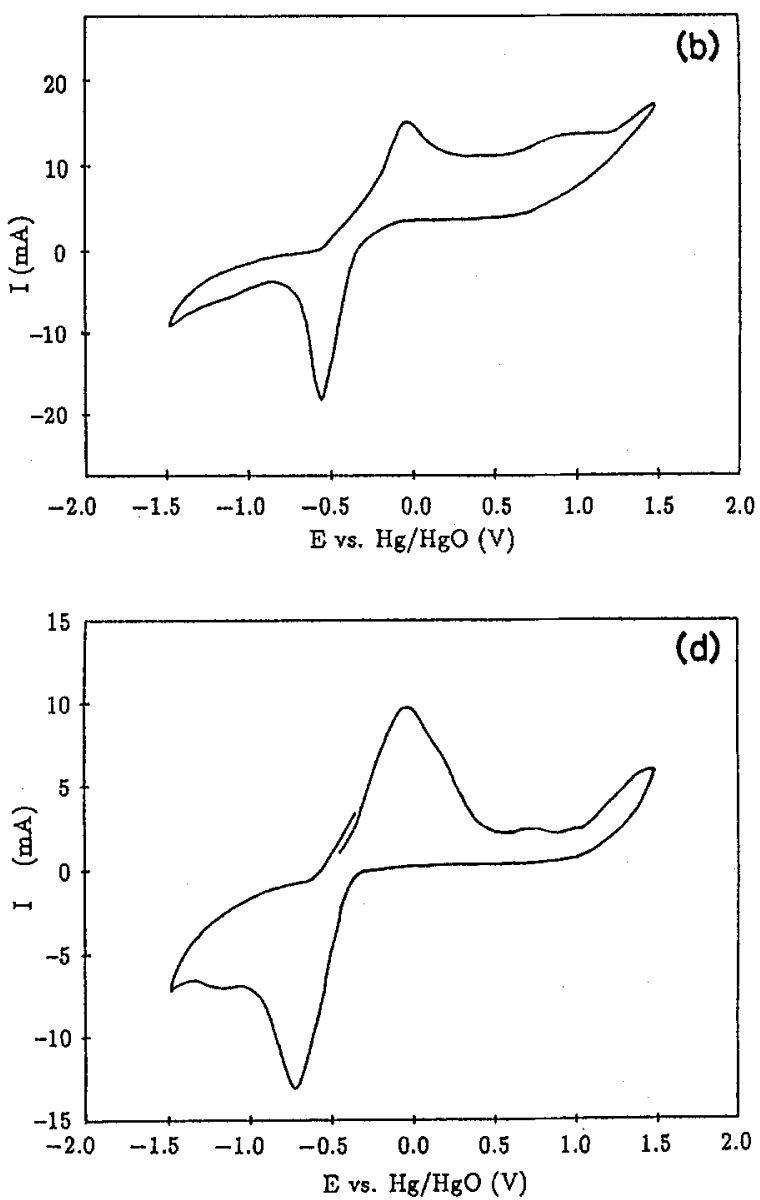

Fig. 10. Cyclic voltammograms for a graphite electrode in different anolyte solutions upon electrolysis for a total amount of charge, $Q$, expressed in units of faraday. Electrode area: $0.0707 \mathrm{~cm}^{2}$; patential sweep rate: $100 \mathrm{mV} / \mathrm{s}$. (a) $1 \mathrm{M} \mathrm{NaHS}$, after $\mathrm{Q}=0.784 \times 10^{-2} \mathrm{~F}$; (b) $1 \mathrm{M}$ NaHS $+1 \mathrm{M}$ $\mathrm{NaOH}$, after $\mathrm{Q}=1.49 \times 10^{-2} \mathrm{~F}$; (c) $0.34 \mathrm{M} \mathrm{Na}_{2} \mathrm{~S}_{4}$, after $\mathrm{Q}=1.175 \times 10^{-2} \mathrm{~F}$; (d) $0.25 \mathrm{M} \mathrm{Na}_{2} \mathrm{~S}_{4}+0.25 \mathrm{M} \mathrm{NaOH}$, after $\mathrm{Q}=0.5 \times 10^{-2} \mathrm{~F}$. Initial anolyte volume in each case was $25 \mathrm{ml}$. 


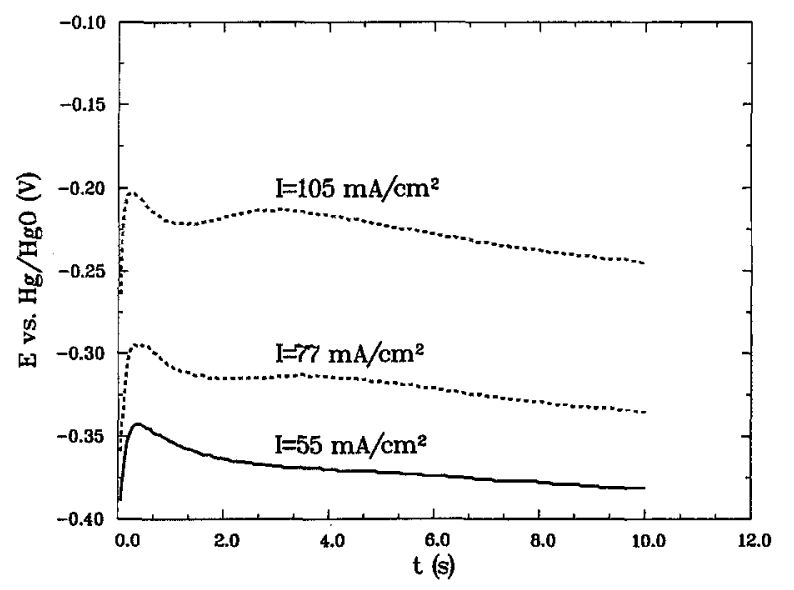

Fig. 12. Typical choronopotentiometric curves over short times for a graphite electrode in freshly prepared anolyte solutions. Plot is shown for the case of a $1 \mathrm{M} \mathrm{NaHS}+1.5 \mathrm{M} \mathrm{NaOH}$ solution mixture.

electrolyte interface. However, because the equilibrium reaction [f] is rapid (12), the concentration of $\mathrm{S}_{2}^{2-}\left(\right.$ or $\mathrm{S}_{x}^{2-}$ ) will increase during this time, with a proportional increase in the current due to reaction [c]. The increasing rate of $\mathrm{S}_{x}^{2-}$ concentration will be accelerated by reaction [f]. By the time the current contributions from reaction [a]-[c] are about equal, the anode potential reaches a maximum and thereafter decreases as reaction [c] concentration polarization decreases. Further electrolysis results in the depletion of $\mathrm{S}^{2-}$, HS $\mathrm{S}^{-}$, and $\mathrm{S}_{2}^{2-}$, so that potential again increases with time. However, as $\mathbf{S}_{2}^{2-}$ accumulates and $\mathbf{S}$ forms, higher polysulfides can be formed via reaction [g], or equivalently, [d] or [e]. Further oxidation of $\mathbf{S}_{x}^{2-}$ to sulfur will increase $\mathrm{S}_{r+1}^{2-}$ concentration; thus, another maximum may appear in the chronopotentiometric curves. Prolonged electrolysis will result in complete conversion of sulfides to $\mathbf{S}_{x}^{2-}$, the current thereafter being used mainly for the oxidation of $\mathrm{S}^{2-}$. As overall concentration polarization increases, so does overall anode potential. Experimentally measured chronopotentiometric behavior of a graphite electrode reveals this general trend of anodic potential with time. We should point out that the oxidation potentials of $\mathrm{S}^{2-}, \mathrm{HS}^{-}$, and $S_{x}^{2-}(x=2 \rightarrow 5)$ species are similar (11), which explains why only one broad anodic peak is observed near the open-circuit potential in the voltammograms.

${ }^{2}$ Electrolysis during continuous passage of $\mathrm{H}_{2} \mathrm{~S}$ through anolyte.-This section represents a summary of initial attempts (13) to reproduce the results of Dandapani et al. (9)

${ }^{2}$ The results that are discussed in this section, although unsuccessful in producing hydrogen and sulfur from $\mathrm{H}_{2} \mathrm{~S}$, should be viewed as evolutionary. The phenomena observed in this scheme led to the successful process described earlier in which a nonsaturated alkaline $\mathrm{H}_{2} \mathrm{~S}$ solution was employed as anolyte, rather than one through which $\mathrm{H}_{2} \mathrm{~S}$ was continuously bubbled.

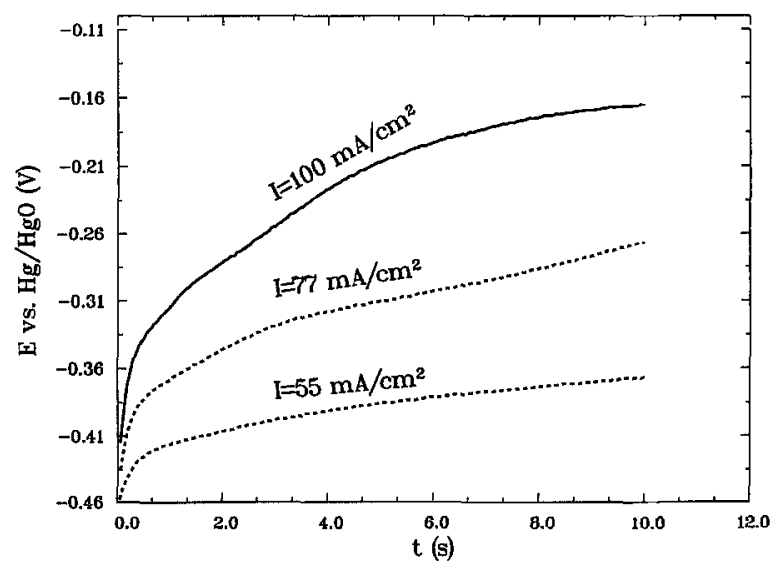

Fig. 13. Corresponding anode potential vs. time plots for a graphite electrode after an amount of charge, $Q=1.49 \times 10^{-2} \mathrm{~F}$, has been passed through the anolyte. $1 \mathrm{M} \mathrm{NaHS}+1.5 \mathrm{M} \mathrm{NaOH}$ solution with on initial volume of $25 \mathrm{ml}$
Table II. Generalized possible anodic reactions during $\mathrm{H}_{2} \mathrm{~S}$ electrolysis in an aqueous alkaline environment.

Electrochemical

$$
\begin{aligned}
\mathrm{HS}^{-}+\mathrm{OH}^{-} \rightarrow \mathrm{S}+\mathrm{H}_{2} \mathrm{O}+2 e^{-} \\
\mathrm{S}^{2-} \rightarrow \mathrm{S}+2 e^{-} \\
\mathrm{S}_{x}^{2-} \rightarrow \mathrm{XS}+2 e^{-} ; \quad x=2-5 \\
x \mathrm{~S}_{x-1}^{2-} \rightarrow(x-1) \mathrm{S}_{x}^{2-}+2 e^{-} ; \quad x=2-5 \\
\mathrm{~S}_{x-1}^{2-}+\mathrm{S}^{2-} \rightarrow \mathrm{S}_{x}^{2-}+2 e^{-} ; x=2-5 \\
\text { Chemical }
\end{aligned}
$$$$
\mathrm{HS}^{-}+(x-1) \mathrm{S}+\mathrm{OH}^{-} \rightarrow \mathrm{S}_{x}^{2-}+\mathrm{H}_{2} \mathrm{O} ; \quad x=2-5
$$$$
\mathrm{S}+\mathrm{S}_{x}^{2-} \rightarrow \mathrm{S}_{x+1}^{2-} ; \quad x=2-4
$$

for $\mathrm{H}_{2} \mathrm{~S}$ electrolysis in an alkaline environment. The anolyte and catholyte were either $1 M$ or $6 M \mathrm{NaOH}$ solutions. High-purity $\mathrm{H}_{2} \mathrm{~S}$ gas was bubbled through the anolyte before and during electrolysis. The experimental arrangement was the same as before, except that a flat plate plexiglass cell containing $100 \mathrm{ml}$ of solution in each compartment was used.

As electrolysis temperature was increased stepwise from $25^{\circ}$ to about $80^{\circ} \mathrm{C}$, there was a marked increase in current at a constant potential or a similar decrease in anode overpotential at a constant current. These observations are consistent with the results of Dandapani et al. (9) and Allen and Hickling (14). However, prolonged electrolysis, even at $80^{\circ} \mathrm{C}$, did not lead to sulfur precipitation. Rather, two distinct gas evolution processes accompanied by a slow increase in anode potential were observed. The first occurred a short time after the start of electrolysis at potentials more positive than $-200 \mathrm{mV} v s$. $\mathrm{Hg} / \mathrm{HgO}$. This gas evolution process stopped when $\mathrm{H}_{2} \mathrm{~S}$ bubbling was discontinued and/or nitrogen was supplied. Since oxygen cannot be evolved at this potential, the process must be associated with sulfur-containing species. Possible gases are $\mathrm{H}_{2} \mathrm{~S}$ and/or $\mathrm{SO}_{2}$, resulting from either, or a combination, of the following reactions

$$
\begin{gathered}
2 \mathrm{HS}^{-} \rightarrow \mathrm{S}+\mathrm{H}_{2} \mathrm{~S} \uparrow+2 e^{-} \\
\mathrm{S}_{2}^{2-}+2 \mathrm{H}_{2} \mathrm{O} \rightarrow \mathrm{SO}_{2} \uparrow+\mathrm{H}_{2} \mathrm{~S} \uparrow+2 \mathrm{H}^{+}+4 e^{-} \\
2 \mathrm{HS}^{-}+2 \mathrm{H}_{2} \mathrm{O} \rightarrow \mathrm{SO}_{2} \uparrow+\mathrm{H}_{2} \mathrm{~S} \uparrow+4 \mathrm{H}^{+}+6 e^{-}
\end{gathered}
$$

In a neutral $p \mathrm{H}$ solution which is reminiscent of an $\mathrm{H}_{2} \mathrm{~S}$ saturated solution, the standard potentials of reactions [2] and [3] are about -0.05 and $-0.07 \mathrm{~V} v$ s. NHE, respectively. Therefore, although all three reactions may possibly take place, the occurrence of [2] and [3] are more likely, especially since no further increase in the potential was observed on extended electrolysis.

The second gas evolution process occurred at a higher anode potential at a later stage of electrolysis and was attributed to sulfur blocking the electrode surface. It was reported earlier (9) that this blocking layer could be eliminated if electrolysis was carried out at a temperature higher than $60^{\circ} \mathrm{C}$. Results at $80^{\circ} \mathrm{C}$ in this work did not confirm this. The potential on a graphite anode always sharply increased with time of electrolysis, and the blocking effect became more pronounced at lower $p \mathrm{H}$ when dissolution of sulfur from the electrode surface could not occur. This phenomenon was only observed when the low overpotential gas evolution process was avoided by starting electrolysis before complete anolyte saturation with $\mathrm{H}_{2} \mathrm{~S}$, so that both gas-evolution processes were not successive. The second gas evolution process occurred at potentials higher than $1.9 \mathrm{~V} v \mathrm{~s}$. $\mathrm{Hg} / \mathrm{HgO}$ and may be attributed to oxygen evolution.

These effects were not dependent on solution concentration, since the same behavior was observed in both $1 M$ and $6 M \mathrm{NaOH}$. However, when metal or metal-alloy anodes $(\mathrm{Ni}$, $\mathrm{Ni}-\mathrm{Cr}$, and $\mathrm{Ti}$ ) were used in place of graphite anode, the 
high anode potential at the end of electrolysis was more pronounced.

\section{Conclusions}

The feasibility of an electrochemical process for the production of hydrogen and sulfur by the decomposition of hydrogen sulfide in an alkaline solution has been demonstrated. For this process to be successful, gas evolution at potentials lower than that for oxygen evolution, passivation of the anode by sulfur deposition, and further oxidation of sulfides and/or polysulfides into sulfur oxyanions must be avoided.

Results have demonstrated that the process previously proposed (11) is feasible by control of $p \mathrm{H}$, temperature, and conditions of electrolysis. In particular, electrolysis in a presaturated solution in the vicinity of equimolar $\mathrm{NaOH}: \mathrm{NaHS}$ concentrations leads to hydrogen and crystalline sulfur production in quantitative yields (at least 95\%). In particular, $\mathrm{H}_{2} \mathrm{~S}$ must not be continuously bubbled into the anolyte during electrolysis so that $\mathrm{pH}$ can be properly controlled and anode passivation can be avoided.

In this work, sulfur was produced in a batch process. To be commercially viable, the process must be made continuous. One approach, described in more detail elsewhere (11), would be to continuously transfer the concentrated caustic, pumped through the membrane to the cathode compartment, to the scrubbing system, maintaining flow so that the solution leaves half-neutralized. Finally, in a practical system, the Nafion membrane may be replaced by an inexpensive microporous separator.

\section{Acknowledgment}

The authors wish to acknowledge technical assistance from the Electron Microscopy Center of Texas A\&M University for the scanning electron microscopy studies. The assistance of Lisa Donaghe in the EDS analysis of the sul- fur samples is greatfully appreciated. Financial support from the Environmental Protection Agency and Lamar River Oaks Travel Incorporated, is greatfully acknowledged.

Manuscript submitted Aug. 7, 1989; revised manuscript received April 7, 1990.

Texas A\&M University assisted in meeting the publication costs of this article.

\section{REFERENCES}

1. J. E. Noring and E. A. Fletcher, Energy, 7, 651 (1982).

2. P. W. Bolmer, U.S. Pat. $3,409,520$ (1968).

3. Ven-Shiang Shih and Jeou-Long Lee, Ind. Eng. Chem. Process Des. Dev., 25, 836 (1986).

4. F. Fischer, U.S. Pat. 1,891,974 (1932).

5. D. W. Kalina and E. T. Maas, Jr., Int. J. Hydrogen Energy, 10, 157 (1985).

6. D. W. Kalina and E. T. Maas, Jr., ibid., 10, 163 (1985).

7. D. C. Olson, U.S. Pat. 4,436,713 (1984).

8. J. Winnick, U.S. Pat. 4,772,366 (1988).

9. B. Dandapani, B. R. Schariifker, and J. O'M. Bockris, in "Advancing Toward Technology Breakout in Energy Conversion," A Symposium of the 21st Intersociety Energy Conversion Engineering Conference, Vol. 1, p. 262 (1986).

10. K. Nygren, W. H. Smyrl, E. A. Fletcher, and R. T. Atanososki, Abstract 549, p. 788, The Electrochemical Society Extended Abstracts, Vol. 88-1, Atlanta, GA, May 15-20, 1988.

11. Z. Mao, A. Anani, R. E. White, S. Srinivasan, and A. J. Appleby, Submitted to This Journal.

12. H. H. Voge, J. Am. Chem. Soc., 61, 1032 (1939).

13. Final report on "Economic Removal of Hydrogen Sulfide from Natural Gas and Oil," Contract No. 68-024529, submitted to EPA, September 1988.

14. P. L. Allen and A. Hickling, Trans. Faraday Soc., 53, 1626 (1957).

\title{
Potential-pH Diagrams for Adsorbed Species \\ Application to Sulfur Adsorbed on Iron in Water at $25^{\circ}$ and $300^{\circ} \mathrm{C}$
}

\author{
Philippe Marcus* and Elie Protopopoff \\ Laboratoire de Physico-Chimie des Surfaces associé au CNRS, Ecole Nationale Supérieure de Chimie de Paris, \\ 75231 Paris Cedex 05, France
}

\begin{abstract}
The principle of equilibrium potential-pH diagrams (Pourbaix diagrams) is extended to the case of two-dimensional species adsorbed on metals. Up to now, the only solid compounds taken into account in these diagrams have been threedimensional compounds. However, species may be adsorbed in $E-p H$ domains where three-dimensional compounds are unstable. The principle of the calculation of the $E-p H$ relations existing at equilibrium in aqueous solution between the dissolved species and the species adsorbed on a metal is presented. The calculation is made for sulfur adsorbed on iron in water $\left(\mathrm{S}_{\mathrm{ads}}-\mathrm{Fe}-\mathrm{H}_{2} \mathrm{O}\right)$, using thermodynamic data for sulfur chemisorption on iron. The resulting $E$ - $p \mathrm{H}$ diagrams for the $\mathrm{S}_{\mathrm{ads}}-\mathrm{Fe}-\mathrm{H}_{2} \mathrm{O}$ system at $25^{\circ}$ and $300^{\circ} \mathrm{C}$ are shown. Formation of adsorbed monolayers of sulfur is predicted in $E$-pH domains where a classical diagram does not predict the formation of sulfide. Direct applications of such diagrams in corrosion, $e . g$. in water at $300^{\circ} \mathrm{C}$, are emphasized.
\end{abstract}

The principle and the use of equilibrium potential-pH diagrams, or Pourbaix diagrams, are well known (1). In these diagrams, potential-pH lines limiting the domains of stability of the various chemical forms of an element in solution, at equilibrium, are calculated from the Nernst law. To our knowledge, the only solid compounds to be taken into account in $E$-pH diagrams have been three-dimensional compounds. However, the formation of a threedimensional (bulk) solid compound $\mathrm{M}_{x} \mathrm{~A}_{y}$ (A may be $\mathrm{H}, \mathrm{O}$, $\mathrm{N}$, or $\mathrm{S}$ ) on a metal $(\mathrm{M})$ is usually preceded by the formation of a two-dimensional phase of $\mathrm{A}$ adsorbed on the metal surface, which is more stable than the bulk compound (2). Thus, adsorbed layers may be formed in $E-p H$ domains where a classical diagram does not predict such

* Electrochemical Society Active Member. phases. This phenomenon must not be neglected because the presence of an adsorbed monolayer can induce marked changes in the reactivity of the metal. As an example, in corrosion, a monolayer of sulfur adsorbed on $\mathrm{Ni}$ or $\mathrm{Ni}-\mathrm{Fe}$ alloys enhances the anodic dissolution and hinders the formation of the passive film, drastically affecting the corrosion resistance of the metal or alloy $(3,4)$.

The aim of this work is to establish the E-pH relations existing at equilibrium in aqueous solution between dissolved species of an element and the element adsorbed on a metal. The principle of the calculation is presented and thereafter applied to the adsorption of sulfur and oxygen on iron in water containing $\mathrm{H}_{2} \mathrm{~S}, \mathrm{HS}^{-}, \mathrm{HSO}_{4}{ }^{-}$, or $\mathrm{SO}_{4}{ }^{2-}$. A similar calculation has also been done for sulfur adsorbed on platinum (5). 